\title{
ANTS DISPERSE THE ELAIOSOME-BEARING EGGS OF AN AFRICAN STICK INSECT
}

\author{
By S. G. COMPTON And A. B. Ware \\ Department of Zoology and Entomology, Rhodes University, \\ Grahamstown, South Africa
}

The seeds of many plants possess elaiosomes which facilitate their dispersal by ants (Beattie, 1985). Here we describe an apparent example of convergence in dispersal mechanisms between kingdoms, where an African stick insect also uses ants to disperse its progeny. We found that the capitulum on the eggs of the stick insect, Bacillus ? coccyx Westwood (Phasmida, Phasmatidae), functions in a similar way as an elaiosome. The eggs are attractive to ants and the capitulum provides them with a handle to carry the eggs. A further parallel with elaiosomes on seeds is that the ants were able to remove and eat the capitulum without reducing egg viability.

Female stick insects are slow moving, often flightless insects and consequently have limited dispersal abilities. This is particularly the case with gravid females, which may be unable to fly even if they possess wings (Bedford, 1978). Stick insect eggs are hard-shelled and often closely resemble seeds, a mimicry which may help reduce predation by insectivorous birds (Carlberg, 1986; Hinton, 1981). They are laid singly, and are often simply dropped or flicked away by the ovipositing female (Bedford, 1978). In many species the eggs have an appendage, the capitulum, which can be detached without reducing their viability (Clark, 1976a, 1976b). The function of the capitulum was discussed by Hinton (1981), who showed that previous ideas about capitula being involved with respiration were incorrect, but concluded that their size and complexity indicated an important, but unknown, function.

\footnotetext{
*Manuscript received 20 May 1991.
} 


\section{NATURAL History}

Bacillus ? coccyx is the most frequently encountered stick insect in the eastern Cape Province of South Africa. A flightless female was collected from fynbos (heathland) vegetation near Grahamstown in March 1990. Over 100 eggs were laid, at a rate of between one and six eggs per day. The female jerked her abdomen during oviposition, flicking the eggs away from her. The eggs resembled brown shiny seeds (Fig. 1) and averaged $2.14 \mathrm{~mm}$ in length (S.D. = $0.20)$ and $2.00 \mathrm{mg}$ in weight (S.D. $=0.13),(\mathrm{n}=10$, ranges $=$ $2.06-2.26 \mathrm{~mm}$ and $1.76-2.19 \mathrm{mg}$ ). The capitula were whiteish with five short lateral ridges (Fig. 2) and had a mean weight of 0.011 $\mathrm{mg}(\mathrm{n}=10$, S.D. $=0.003$, range $=0.007-0.015 \mathrm{mg})$, about $0.7 \%$ of the total weight of the egg.

\section{InTERACTIONS Between Ants and Stick Insect EgGs}

In natural vegetation near Grahamstown we examined the responses of three common fynbos ant species to the eggs of $B$. ? coccyx. Foraging ants were offered a choice between pairs of eggs, one intact, the other with its capitulum removed. Pheidole megacephala Fabr. minor workers showed equal interest in the two groups of eggs (Table 1). However, in all twenty replicate pairs only the intact eggs were carried away by the ants, while the eggs without their capitula were left behind. All the eggs were taken into their nest nearby. Similar results were obtained using the ant Acantholepis capensis Mayr (Fig. 3), although one worker did manage to carry a capitulum-free egg (Table 1). Workers of Crematogaster peringueyi Emery, the largest of the three species, were also interested in the eggs, but had difficulty gripping the capitula (Table 1).

The effect of capitulum removal on egg viability was also examined. Ants were used to remove the capitula and the eggs were then kept under the same laboratory conditions as control eggs. Controls had a hatching rate of $76 \%$, experimental eggs $85 \%$ (41:13 and 11:2, Chi square $=0.09, \mathrm{P}>0.05)$. Hatching success of the two groups was therefore similar, with no indication that capitulum removal reduced survival.

A third group of eggs was left to hatch in a laboratory colony of A. capensis. The capitula were chewed off and the eggs remained 




Fig. 1. Lateral view of an egg of $B$. ? coccyx showing the terminal capitulum.

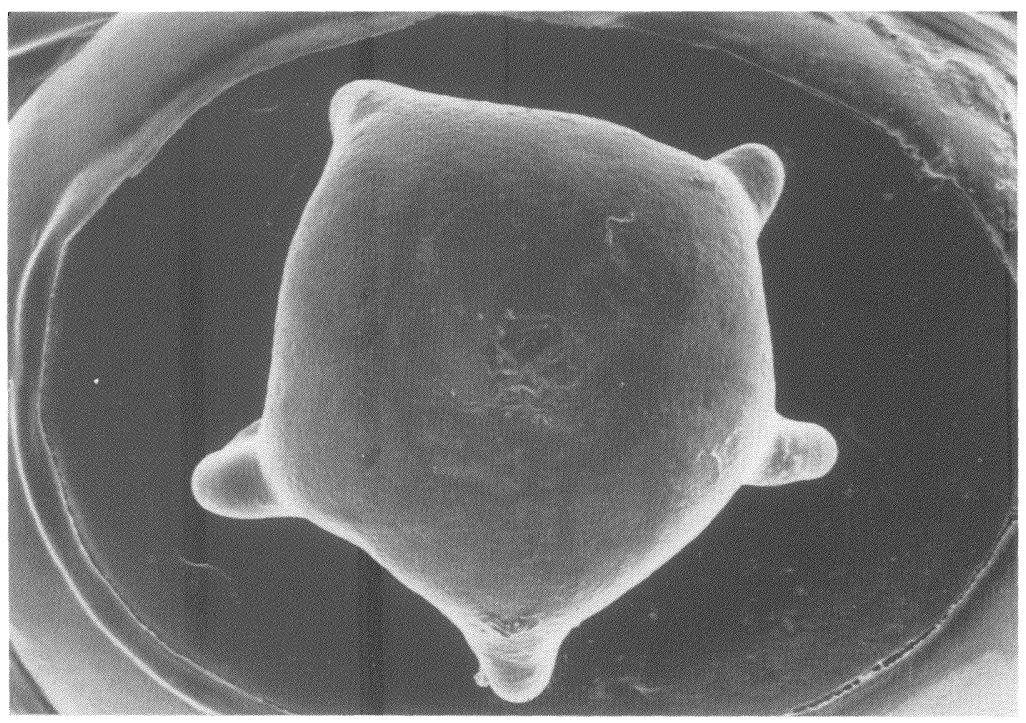

Fig. 2. View from above of the egg capitulum of B. ? coccyx. 
Table 1. The responses of ants to eggs of the stick insect Bacillus ? coccyx. In an area of natural vegetation, ants were offered a choice between pairs of eggs, one intact, the other with its capitulum removed. Ant contacts with eggs were recorded until the first egg was removed. No differences were recorded in the rate of ant contacts with control and capitulum-free eggs (Mann-Whitney test, $\mathrm{P}>0.05$ ). Eggs with capitula were more likely to be carried away by $P$. megacephala and A. capensis (both $\mathrm{Chi}^{2}, \mathrm{P}<0.001$ ).

\begin{tabular}{lcccccc}
\hline Ant species & Replicate & \multicolumn{3}{c}{ Intact eggs } & \multicolumn{2}{c}{ Capitulum-free eggs } \\
egg pairs & $\begin{array}{c}\text { Contacts } \\
\text { (mean) }\end{array}$ & $\begin{array}{c}\text { No. } \begin{array}{c}\text { Mean removal } \\
\text { removed } \\
\text { time (secs.) }\end{array} \\
\text { (mean) }\end{array} \begin{array}{c}\text { No. } \\
\text { removed }\end{array}$ \\
\hline $\begin{array}{c}\text { Pheidole } \\
\text { megacephala }\end{array}$ & 20 & 5.9 & 20 & 186.0 & 5.9 & 0 \\
$\begin{array}{c}\text { Acantholepis } \\
\text { capensis }\end{array}$ & 21 & 1.2 & 20 & 621.3 & 1.0 & 1 \\
$\begin{array}{c}\text { Crematogaster } \\
\text { peringueyi }\end{array}$ & 4 & $18.5^{*}$ & 0 & - & 19.0 & 0 \\
\hline
\end{tabular}

${ }^{*}$ Contacts during the first two minutes of exposure.

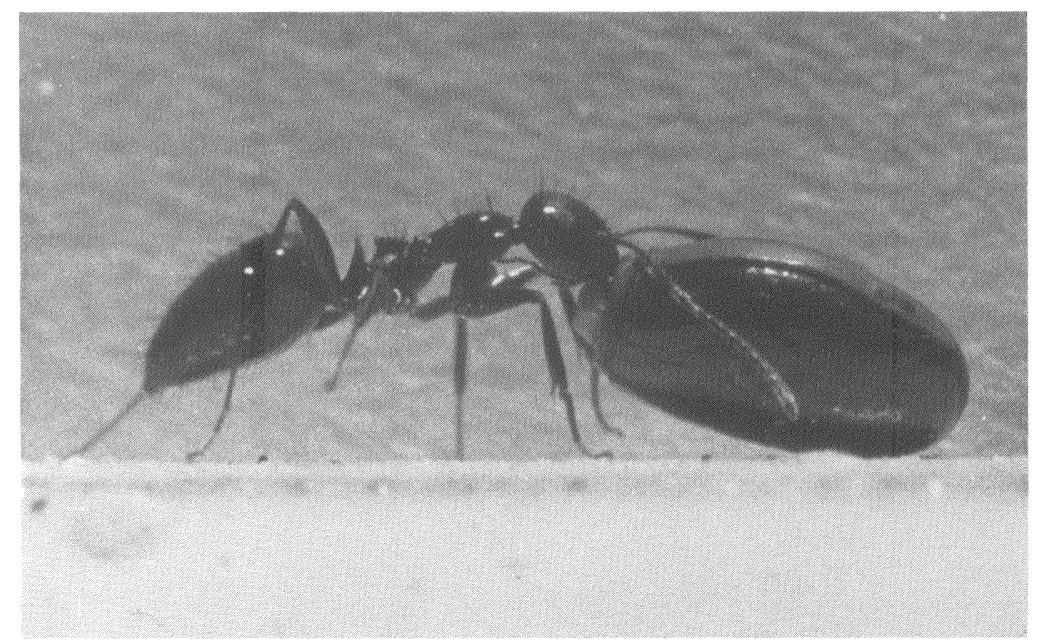

Fig 3. Worker Acantholepis capensis using the capitulum to carry an egg of B. ? coccyx. 
in the nest. Eight of the ten eggs subsequently hatched. The first instar stick insect larvae were not molested, and seemed to be ignored by the ants.

\section{DISCUSSION}

Seed dispersal by ants (myrmecochory) typically involves the collection of inedible seeds bearing ant-attractant elaiosomes, the removal of food bodies in the nest, and subsequent rejection of the seeds. The capitulum of $B$. ? coccyx functions in the same way as an elaiosome and the ants disperse this insect's eggs in a way which closely parallels myrmecochory. The general egg surface is hard and shiny, which probably prevents the eggs from being damaged by the ants, while the capitulum acts as a handle which allows the eggs to be carried to the nest.

The dispersal of seeds by ants is considered to benefit the plant through the avoidance of predators, competition and fire and through the deposition of seeds in nutrient rich sites (Beattie, 1985; Bennett and Krebs, 1987). Except for the latter, similar benefits may accrue to stick insect eggs dispersed by ants. Avoidance of inbreeding may be a further benefit. Due to the sedentary nature of adult female stick insects, their life-long egg production will normally be aggregated, making it easier for parasitoids to find the eggs. At least two groups of small wasps exclusively parasitise stick insect eggs (Riek, 1970). By dispersing the eggs, ants should reduce both parasitism and the possibility of any competition between larvae. In addition, eggs inside ants' nests will be protected from fire, a regular occurrence in fynbos vegetation. By eating the capitula the ants presumably also benefit, and consequently the relationship is mutualistic.

Fynbos is known to be rich in plant species that rely on myrmecochory (Bond and Slingsby, 1984). The discovery of a fynbos stick insect using this form of dispersal may therefore not be coincidental, particularly as fires are a regular occurrence in fynbos vegetation and fire avoidance is one of the postulated advantages of ant dispersal. Nonetheless, eggs bearing capitula have been recorded in five of the eleven subfamilies of Phasmatidae (Clark, 1976a). If their general function is to act as elaiosomes then myrmecochory may be widespread among stick insects. 
A danger with using ants for dispersal is that stick insects hatching in or near ants' nests will risk immediate predation. In the case of $B$. ? coccyx the larvae were ignored by ants, suggesting that antrelated adaptations may be present. Young larvae of some other species are known to be ant mimics (Carlberg, 1986), and ant-stick insect relationships may yet hold further surprises.

\section{SUMMARY}

The capitulum on the eggs of the South African stick insect Bacillus ? coccyx functions in a similar way as elaiosomes on seeds. Ants use the capitulum to carry the eggs, removing and eating it without reducing egg viability.

\section{ACKNOWLEDGMENTS}

We thank H. R. Hepburn and J. H. Cushman for their comments on the manuscript, C. Avierinos for collecting stick insects, A. J. S. Weaving (Albany Museum) for taking photographs of the eggcarrying ants and H. G. Robertson (South African Museum) for ant identifications.

\section{REFERENCES}

BeAtTie, A.J.

1985. The Evolutionary Ecology of Ant-Plant Mutualisms. Cambridge University Press, Cambridge U.K.

BEDFORD, G.O.

1978. Biology and ecology of the Phasmatodea. Ann. Rev. Entomol. 23: 125-150.

BenNetT, A. AND KReBs, J.

1987. Seed dispersal by ants. Trends in Ecol. Evol. 2: 291-292.

Bond, W. AND SLingsby, P.

1984. Collapse of an ant-plant mutualism: The Argentine ant (Iridomyrmex humilis) and myrmecochorous Proteaceae. Ecology 65: 1031-1037.

CARlberg, U.

1986. Phasmida: A biological review (Insecta). Zool. Anz. 216: 1-18.

Clark, J.T.

1976a. The capitulum of phasmid eggs (Insecta: Phasmida). Zoo. J. Linn. Soc. 59: $365-373$.

1976b. The eggs of stick insects (Phasmida): a review with descriptions of the eggs of eleven species. Syst. Entomol. 1: 95-105.

HinTON, H.E.

1981. Biology of Insect Eggs. Pergamon Press, Oxford. 
RIEK, E.E.

1970. Phasmatodea (Stick insects). Pages 348-359 in C.S.I.R.O. (ed.) The Insects of Australia. Melbourne University Press, Melbourne. 

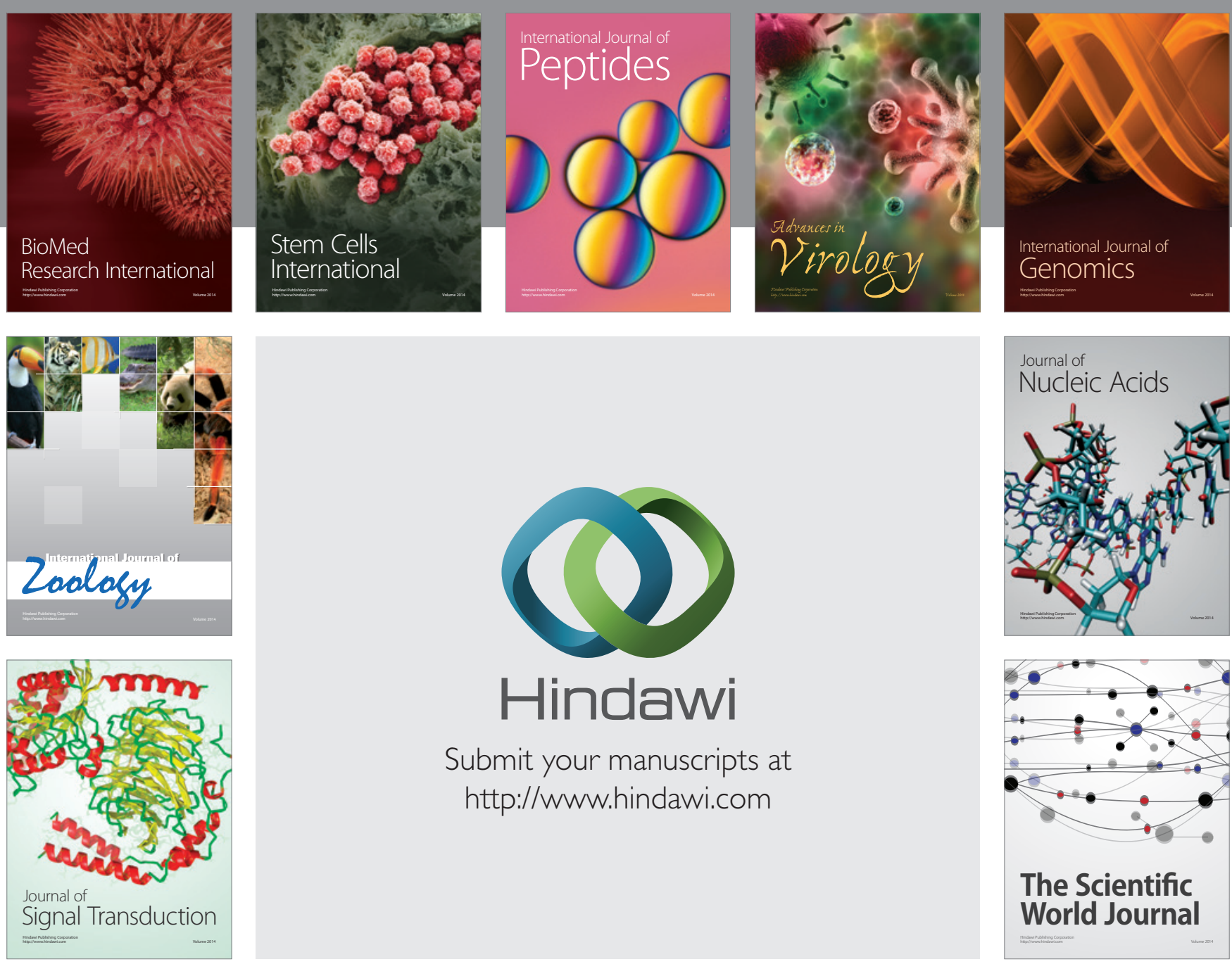

Submit your manuscripts at

http://www.hindawi.com
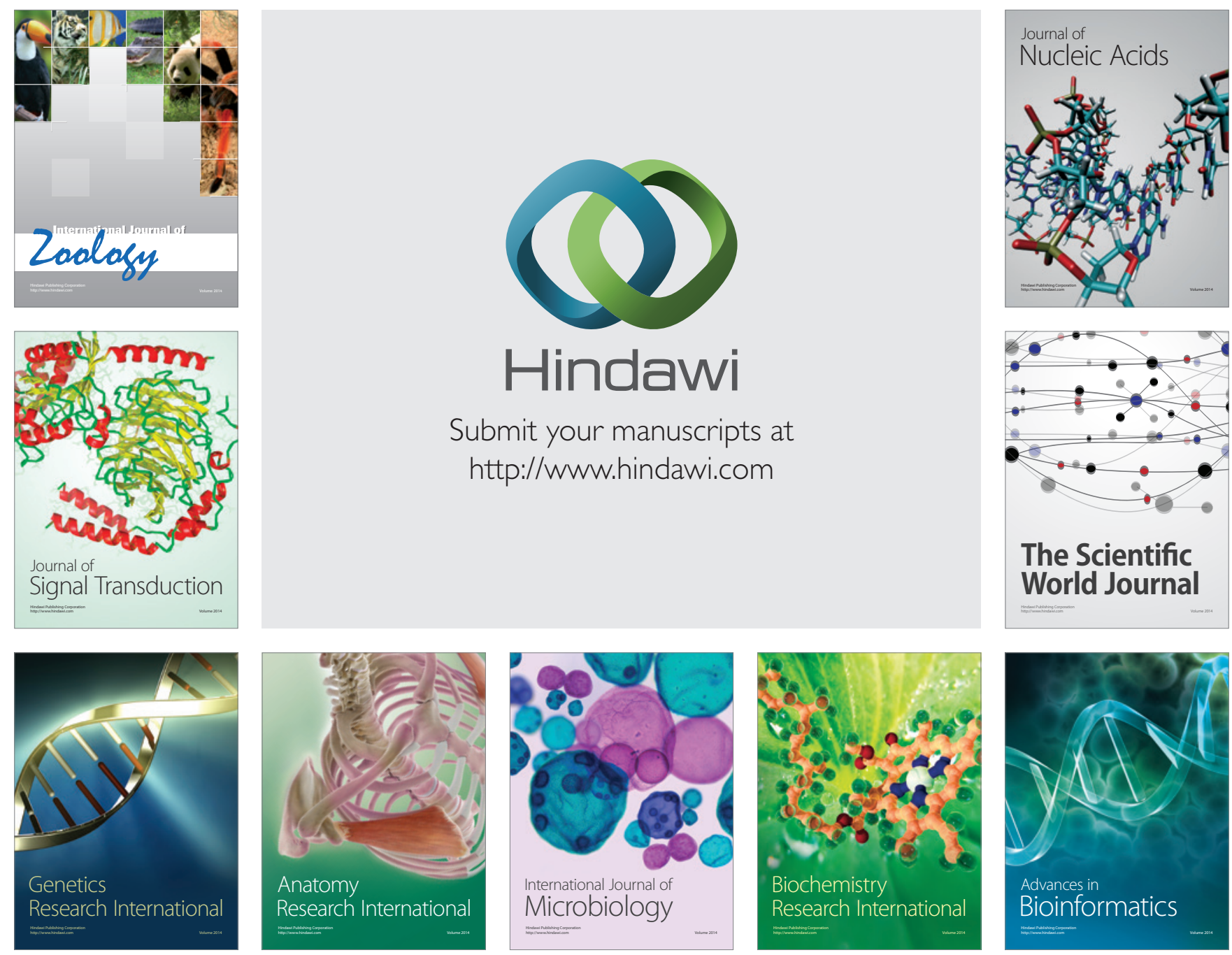

The Scientific World Journal
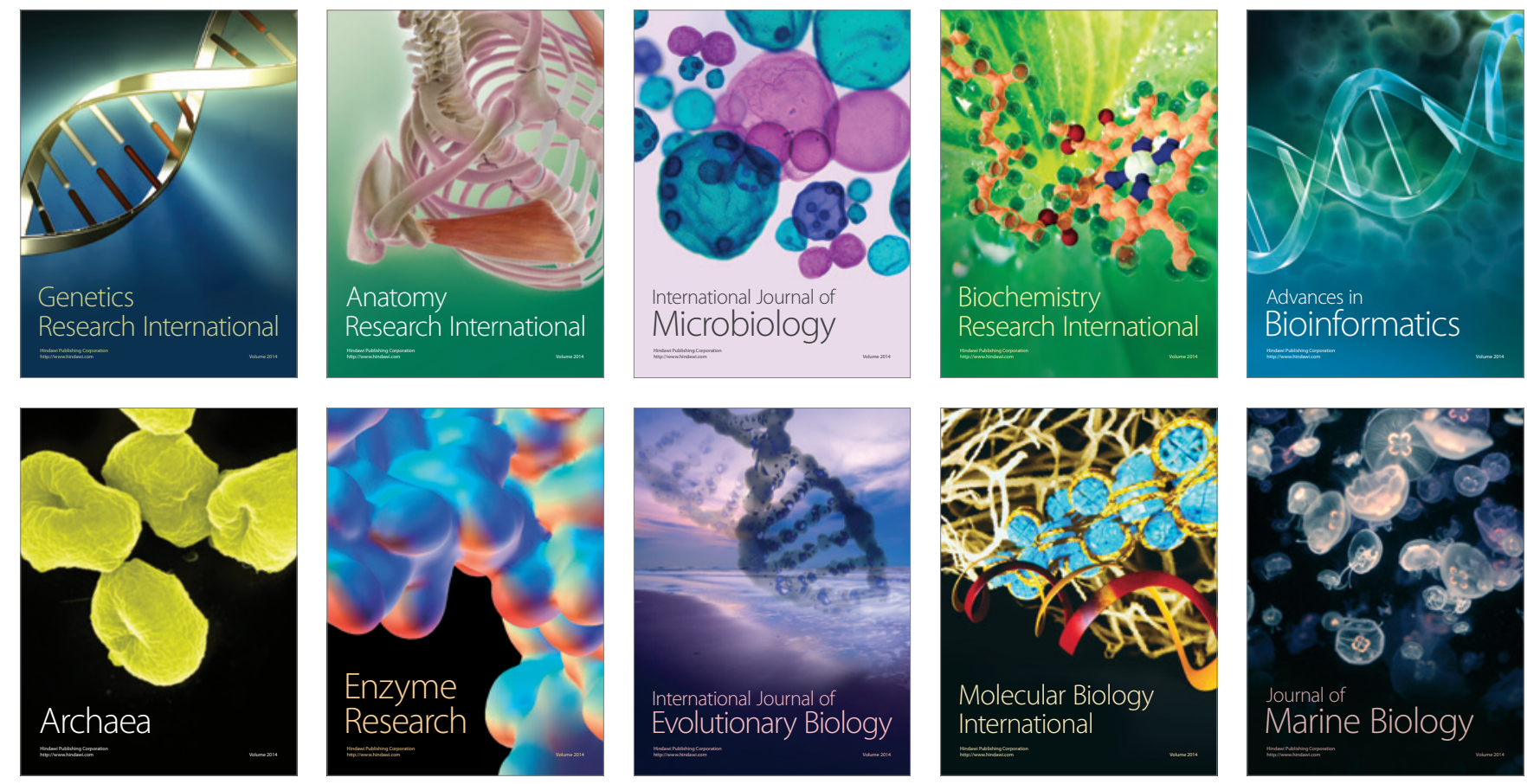